\title{
The role of socio-economic status in the utilization of health care services in rural areas in Bauchi State
}

\author{
Abdul-Baqi, Alhaji Magaji ${ }^{\mathrm{a}, \mathrm{b}}$ and Nwajei, Samuel $\mathrm{D}^{\mathrm{b}}{ }^{\text {, Igumbor, Eunice U. }}{ }^{\mathrm{b}}$ \\ a jesumowo0630@gmail.com,sendmail2magaji@gmail.com \\ ${ }^{a}$ College of Health Technology, Ningi, Bauchi State, 740001 \\ ${ }^{b}$ Department of Public and Community Health, Novena University, Ogume, 320001
}

\begin{abstract}
Several socio-economic factors have been indicated as factors that are responsible for the utilization and outcome of health care services. The study aims at investigating the socio-economic factors that affect the utilization of health care services by inhabitants of rural areas of Bauchi State. The study engaged the survey design. A total of 3447 respondents were sampled for the study. The procedure used is the simple random sampling procedure. A wellstructured questionnaire was used to elicit data for the study. $42 \%$ of the respondents were males while $58 \%$ of them females. The result obtained shows that education (47.4\%); employment status (52.5\%) and house ownership status $(67.7 \%)$ are the socio-economic factors that significantly necessitated the utilization of health care services by rural dwellers of Bauchi State. Education status, Occupation, Income, education, healthcare, type of house, age, marital status and insurance, do not have influence on the utilization of health care services $(\mathrm{P}>0.05)$. In conclusion, the utilization of health care centers in Bauchi State is very low among the rural dwellers. The non-educated or half literate, the unemployed and those who live in rented homes should be encouraged to utilize health facilities the more. Also, the influence of other socio-economic factors on health facilities utilization should be studied.
\end{abstract}

Key Words: socio-economic, health, utilization, services, factors

\section{Main text}

\section{Introduction}

The choice of health facility varies from one person to another and from one place to another, and it also depends on certain predisposing factors to the use of health facilities (Oluyemi, Abubakar, Abdullateeef, Akindele, Adejoke and Kairi, 2018). Actual utilization of health services will differ in accordance with various factors. Hence, when a country is not interested in merely providing physical access, but also in ensuring that modern health services are used by the population, it becomes important for such country to also understand the factors affecting health care utilization. These factors range from age, proximity, health status, income etc., most of which can be grouped as socio-economic factors (Gooch, 1991). Gooch (1991) emphasized that the impact of health service research has been difficult to measure, but stated that such research contributes to an improved system of care. 
Health Care Utilization according to Carrasquillo (2013) is "the quantification or description of the use of services by persons for the purpose of preventing and curing health problems, promoting maintenance of health and wellbeing, or obtaining information about one's health status and prognosis. It refers to the use of health care services. Utilization can be described as the use or amount usage per unit population of health services. It stated that in health care, utilization is defined as "the consumption of services or supplies such as the number of office visit a person makes per year with a health care provider, the number of prescription made or the number of days a person is hospitalized. Carrasquillo (2013) stated that utilization is often reported as the number of services used over a period of time divided by the population denominator. Or the percentage of persons who use a certain service divided by individuals eligible to use the service. Oladipo (2014) stated that within the developing countries, differences in health status exist, based on indices such as infant mortality, young and child mortality and maternal mortality. Serious attention is required in improving quality of healthcare services to enhance it utilization, the study therefore seek to investigate the socio-economic factors that affect the utilization of health care services by inhabitants of rural areas of Bauchi State.

\section{RESEARCH QUESTION}

What are the socio-economic factors that necessitate the utilization of health care services by rural dwellers of Bauchi State?

\section{RESEARCH HYPOTHESIS}

Socio-economic factors do not have significant influence on the utilization of health care services by rural dwellers of Bauchi State?

\section{Literature Review}

Generally Health service providers in rural areas struggle to maintain primary health services because of some socio-economic factors. For instance, the residents in southern Nigerian are better educated with higher likelihood of embracing western lifestyles which involves utilizing health facilities than in the rural northern.

Several factors have been indicated as factors that are responsible for the utilization and outcome of health care services. For instance, available reports reveal that patients' satisfaction is associated with physician's advice and treatment, explanation provided and their listening abilities. Among others, the identified factors that influence 
people's choice of care options in hospitals includes cost, care options available, economics, beliefs/ culture and mechanisms of referral (Omorogbe, 2017). Omorogbe (2017) also recommended that socioeconomic factors as they affect outcome of in-patients' and utilization of the available health care services be integrated into their medical services in the hospital organization providing health care services especially in teaching hospital.

The socio-psychological approach sees utilization of health services from the perspective of a person's Knowledge, beliefs and attitude concerning the symptoms he/she is experiencing; attitude towards the physician and the person's definition of sickness and determination of the necessity for professional care. The organizational approach examines the structure of the health care delivery system; and the social system approach view the health care service system utilization as consisting of interrelated components such as physicians and facilities that interact with one another and the population at large (Anderson, 1973).

According to Fang et al (2014), some of the identified socio-economic factors include medical insurance, income, proximity, free health care, and influence from third party. The report of Xu et al (2006) whose study evaluated the impact of social health insurance on the use of health services and on financial protection in Vietnam indicated that the insurance coverage only increased access to public facility services but not to private facility services. They also found that the insured are also better protected from large financial burden due to health expenditures than the uninsured. Babazono (2008) found that average monthly salary showed a high positive correlation with utilization of dental services. They found that if the average monthly salary were reduced, a great number of patients would reduce their dental services sought for in the health centers. They therefore concluded that a low salary appears to discourage patients from seeking medical and dental services in Japan. Saeed et al. (2016), in their study found that health status is a very strong determinant of the type of healthcare services preferred by older adults Ghanaians found that People with higher income preferred the private health facilities, while those with lower income rather use the traditionalist or public hospitals. The study of NCHS (2017) reveals that income correlates highly with risk factors for chronic disease: noting that people, who have lower family income have higher rates of heart disease, stroke, diabetes, or hypertension, and have four or more common chronic conditions. NCHS (2017) found that people with low income were more likely to delay in receiving medical care due to the cost than those with higher income. They therefore concluded that the health-care needs of those under the poverty level are still being unmet because of their less utilization of medical facilities. 
It is impossible to access health care if it's nonexistent in a location. Although there may be health centers in some rural area, access to care might be impeded by other barriers. One is inadequate transportation, either because travel time is excessive, because no public transportation is available and the person does not have a car or other alternative transportation, or because the cost of transportation is high (MACPAC, 2016; NCHS, 2016).

Bakeera et al (2009) in their study also found that the poorest wealth category identified the availability of free public care as enabling to the use of both preventive and curative services; while high cost was identified as a barrier to the adoption of certain preventive actions such as use of mosquito nets and condoms. High cost was also a barrier to treatment of both acute and chronic conditions.

A study conducted by Awoyemi (2011) in Kogi State, on the effect of distance on the utilization of healthcare services showed that public facilities compared to private facilities were preferred on account of cost of accessing health service. Cost was also suggested as a major factor for utilization of public rather than private facilities by respondents in their economically productive years.

According to Girma Jira and Girma (2011) as the need for and or utilization of health care changes with age, gender, and marital status, utilization of health services also conforms accordingly. Studies in general found a relationship between age of patients and utilization of health care services. Other predisposing factors like education and family belief have been seen to affect utilization of health services. For instance, a study in Ethiopia revealed that educational status of the mothers has a statistically significant association with the utilization of safe delivery services. Lack of finance may lead to self-medication using modern pharmaceuticals and traditional medicines as observed in North West Ethiopia (Girma et al., 2011).

Fang et al (2014) in his study found that age was a statistically significant factor that could influence the utilization of health services. Age was found to be a negative predictor of utilization health services. The study of Adam and Awunor (2014) on the perception of Factors affecting utilization of Health services in rural community in Southern Nigeria reveals that age is not a predisposing factor to health care service utilization.

Women overall have higher health-care utilization than men. Although it had been thought that women receive health care primarily during childbearing years for reproductive health, many health-care utilizations occur during and after menopause for such issues as cardiovascular disease and osteoporosis (Owens, 2008). 
Among people 18-64 years old, women have higher rates of disability and self-reported fair or poor health status. Among all people 18 years and older, women are more likely to delay or not receive care, or to not receive prescription drugs, because of cost. Women are more likely to have a health-care visit in a given year, to have 10 or more visits, and to have a hospitalization or ED visit (NCHS, 2016). Most findings indicate that although women utilize health-care resources at greater rates, health-care needs go unmet

Mohammadbeigi et al (2015) found that results did not show evidence of sex disparity in the access and utilization of OHC in Iranian children. According to Uchendu et al (2013), a large family would not easily utilize health care service because of the financial cost. Although in their study, Uchendu et al (2013) did not find any statistically significant association between family size and health care utilization. Bakeera et al., (2009) found that the 'poorest' wealth category and large families was keen to utilize free public health services. Conversely, there are perceptions that public health facilities were perceived to offer low quality care with chronic gaps such as shortages of essential supplies. In addition to individual material resources and the availability of free public healthcare services, social resources are perceived as important in overcoming utilization barriers. Bour (2004) also found that family size significantly influenced the utilization of health services by women in Ghana, and Gan-Yadam et al (2012) found that having more than 5 household members was a predisposing factor to utilization of health facilities.

The study of Nigussie, Haile and Mitik (2014) revealed that educational status of the mothers has a statistically significant association with the utilization of safe delivery services. Lack of funds may lead to self-medication using modern pharmaceuticals and traditional medicines as observed in North West Ethiopia. Mohammadbeigi et al (2015) in their study found that educational level did not influence access to and utilization of public healthcare facilities.

Rumun (2014) stated that Religion takes the boundless and binds it into the limitations of language and culture, even as it may also transform culture. Schiller and Levin (1988) found that over three-quarters of respondents in their study reported significant religious differences in rates of utilization They found that of the three religious groups studied (typically Protestant vs Catholic vs Jewish), the Jew are higher utilizers of health care services than the Catholics and protestants.

Health literacy broadly refers to the factors that affect a person's ability to access, process, understand communicate about health information to make informed decisions.

Mwonjoria (2014) also found that top most factor considered in utilizing health care facilities is the competence of 
the healthcare staff in making the correct diagnosis and prescription and the wait time. This according to Jayadevappa and Chhatre (2011) is a patient-centered approach. Thus Hsu (2010) posited that efficiency level of a health care facility will determine the level of penetration and output and this will directly affect the service delivery and Utilization.

The Utilization of health facilities by community members also depends on the attitude of the health care workers. Moyer et al (2014) found that despite the hob of health workers to provide health services to all community members, attitudes influenced by societal norms and beliefs among Health workers can constrain health care delivery and utilization and impact the quality of care both and provision of certain health services. The type of environment people live in will affect the way they utilize health care facilities, as a poor environmental quality has its impact on the people (Healthy people 2020, 2018).

Health services utilization (HSU) is an important health outcome indicator (Ngwakongnwi, 2017). Prosser (2007) in her study on the utilization of health and medical health care seeking behaviour and unmet health needs in rural areas of kenya, found that about $70 \%$ to $80 \%$ of the people living in rural areas of Kenya who were sick utilized the formal healthcare facilities over informal services.

Generally, in Nigeria, it has been found that people hardly visit health facilities unless they are seriously ill, as majority believes that seeking health care in health facilities is too costly. In situation of illness, Ngugi et al (2017) reported a utilization level of 76.7\%, Ministry of Health in Kenya (2003) reported a 77.8\% level of utilization of health facilities, Prosser (2007) also reported a utilization of level of 53\%. A study conducted by Onyebeho et al (2016) revealed that only 50\% of the respondent utilized health care facilities when they are ill.

Literature reviewed so far, have indicated factors that affects health care utilization varies from place to place, most of the literature reviewed were in other African countries and southern part of Nigeria. There is paucity of information about the studies conducted in the rural sections of the northern part of Nigeria. It is therefore necessary to study the rural areas of the Bauchi State to determine if the factors affecting the utilization of healthcare facilities are similar to those in the reviewed literature.

\section{Methods}

\section{Study Design/ Sample size}

The design for this study is the survey design. Using a simple random sampling technique, 3 local government areas were selected from each senatorial district. 
The formula used to determine the sample size of quantitative data iis:

$\mathrm{n}=\mathrm{z}^{2} \mathrm{pq} / \mathrm{d}^{2}$

$\mathrm{d}=$ degree of precision of the study

$\mathrm{z}=$ standard normal deviation corresponding to $95 \%$ confidence interval which is 1.96

$\mathrm{p}=$ population of $50 \%$

$\mathrm{q}=(1-\mathrm{p})$

$\mathrm{n}=(1.96)^{2} \times 0.5 \times 0.5 /(0.05)^{2}=384$

$\mathrm{n}_{\mathrm{o}}=384$

\section{Sample size for each LGA}

$\mathrm{n} / 1+\left(\mathrm{n}_{\mathrm{o}}-1 / \mathrm{pop}\right)$

For southern zone $=384 / 1+(384-1) / 164169=383$

For 3 affected Local Government $=383 \times 3=1149$

For northern zone $384 / 1+(384-1) / 10142=7383$

For 3 affected Local Government $=383 \times 3=1149$

For central zone $=384 / 1+(384-1) / 164169=383$

For 3 affected Local Government $383 \times 3=1149$

Total $=3447$

A total of 3447 respondents were sampled for the study. The procedure used is the simple random sampling procedure.

\section{Study Area}

Bauchi State is a State in northern Nigeria with its capital in Bauchi. Formed in 1976, it originally involved Gombe State, which became distinct State in 1996 (Bauchi State Government, 2018). The State occupies an area of land totaling $49,119 \mathrm{~km}^{2}\left(18,965 \mathrm{sq}^{2}\right)$ representing about $5.3 \%$ of Nigeria's total land mass and is located between latitudes $9^{\circ} 3^{\prime}$ and $12^{\circ} 3^{\prime}$ north and longitudes $8^{\circ} 50^{\prime}$ and $11^{\circ}$ east. The state is bordered by seven states, Kano and Jigawa to the north, Taraba and Plateau to the south, Gombe and Yobe to the east and Kaduna to the west. It spans between two vegetation zones namely the Suan Savannah and the Sahel Savannah (Bauchi State Government, 2018).

\section{Study Population}

The targeted population of the study is the $2,196,533$ adult, which make up $42.06 \%$ of the adult living in the rural areas of Bauchi state.

\section{Research Instrument}


A well-structured questionnaire was used to elicit data for the study. The Instrument Titled "Questionnaire on Factors Affecting the utilization of Healthcare Facilities in Rural Areas. The Instrument is divided into Four Section. The First Section (Section A) deals with the demographic and general information of the respondents. Variable such as age, gender, educational level was addressed in this section. The Second Section (Section B) addresses the living condition of the respondents. Variables addressed here are ownership of house, type of toilets used, access to safe drinking water, etc. The Third Section (Section C) addresses the health utilization of the health centers, while the Fourth Section (Section D) address the various factors that can influence the respondent use of health facilities around them.

\section{Validity of the Research Instrument}

To determine the validity of the instrument, the researcher gave the questionnaire to the supervisor and other experts in related fields to ascertain the face validity of the instrument.

\section{Reliability of the Research Instrument}

The reliability index was determined using Cronbach's alpha test of internal consistency. The instrument was reliable at an alpha value of 0.861 .

\section{Method of Data Collection}

The questionnaires were administered to adults in rural areas in Bauchi State. This questionnaire were administered by the researcher and some research assistants that were trained to evaluate them and interpret the content of the questionnaire to the respondents in the local dialect (for those who cannot read or understand English Language).The questionnaires were collected personally by the researcher and assistants immediately the questionnaires were filled by the respondents. All questionnaires collected from the respondents were received by the researcher, and data retrieved from the questionnaires were collated for analysis.

\section{Method of Data Analysis}

The data from the study were presented in tables. Percentages and frequencies were used to answer the research questions, while Pearson's Product Moment Correlation analysis was used to test the hypothesis. The analysis was carried out using SPSS version 25.

\section{Significance}

The result of the research work will help enlighten government on how to tackle problem that affects the utilization of Healthcare facilities in Bauchi state and the country at large.

\section{Results}




\section{Demographic variables of respondents}

The respondents' gender, age, marital status, educational status and occupation. The percentages of respondents based on these classification is presented in Table 1

Table 1: Demography of respondents

\begin{tabular}{|c|c|c|c|}
\hline & Variables & $\mathbf{N}$ & \\
\hline Gender & Male & 1447 & 42.0 \\
\hline \multirow{7}{*}{ Age } & Female & 2000 & 58.0 \\
\hline & under 20yrs & 400 & 11.6 \\
\hline & $20-25 y r s$ & 600 & 17.4 \\
\hline & $26-30 y r s$ & 447 & 13.0 \\
\hline & 31- 35yrs & 850 & 24.7 \\
\hline & 36- 40yrs & 700 & 20.3 \\
\hline & above $40 y r s$ & 450 & 13.1 \\
\hline \multirow{4}{*}{ Marital Status } & Single & 200 & 5.8 \\
\hline & Married & 2500 & 72.5 \\
\hline & Divorced & 400 & 11.6 \\
\hline & Separated & 347 & 10.1 \\
\hline \multirow{4}{*}{$\begin{array}{l}\text { Educational } \\
\text { Qualification }\end{array}$} & No formal education & 1687 & 48.9 \\
\hline & Primary & 1050 & 30.5 \\
\hline & Secondary & 450 & 13.1 \\
\hline & Tertiary & 260 & 7.5 \\
\hline \multirow[t]{5}{*}{ Occupation } & Unemployed & 1500 & 43.5 \\
\hline & Farmers & 847 & 24.6 \\
\hline & civil servant & 400 & 11.6 \\
\hline & work in a private company & 150 & 4.4 \\
\hline & self employed & 400 & 11.6 \\
\hline
\end{tabular}

Table 1 shows that $42 \%$ of the respondents are males while $58 \%$ of them are females. 11.6 were under the age of 20 , $17.4 \%$ were between 20 and 25 years of age, $13 \%$ were between 26 and 30 years of age, $24.7 \%$ of the respondents were between the ages of 31 and 35 years, $20.3 \%$ between the ages of 36 and 40 while the remaining $13.1 \%$ were above the age of 40 . When classified based on their marital status, only $5.8 \%$ of the respondents were singles, $72.5 \%$ are married, $11.6 \%$ divorced and $10.1 \%$ of the respondents are separated from their spouses.

Close to half of the respondents sampled (49.9\%) do not have any form of formal education, only $30.5 \%$ had primary education as their highest educational qualification, $13.1 \%$ had secondary education and only $7.5 \%$ studied up to the tertiary level of education. Based on the occupation of the respondents, $43.5 \%$ are unemployed, $24.5 \%$ are 
farmers, $11.6 \%$ are civil servants, $4.4 \%$ works in some private companies around and $11.6 \%$ are self-employed.

\section{ANSWERING RESEARCH QUESTION}

What are the socio-economic factors that necessitate the utilization of health care services by rural dwellers of Bauchi State?

Table 2: Socio-economic factors that necessitate the utilization of health care services by rural dwellers of Bauchi State

\begin{tabular}{lll} 
Factors & \multicolumn{1}{c}{ Utilization } & \multicolumn{1}{c}{$\mathbf{N}(\%)$} \\
Education & \multicolumn{1}{c}{$\mathbf{N}(\%)$} & Non educated 1589 (46.1) \\
Occupation & Educated 1633(47.4) & Unemployed 1414 (41.0) \\
Income & Employed 1808(52.5) & Low 1887 (54.7) \\
Spending on monthly basic food & Not low 1335(38.8) & Low 1997 (57.9) \\
House ownership & High 1225 (35.5) & No 888(25.8) \\
Access to safe drinking water & Yes 2334 (67.7) & No 1722(50.0)
\end{tabular}

The results presented in Table 2 shows that the factors that influence the utilization of health care services by rural dwellers of Bauchi State. The result obtained shows that, education (47.4\%); employment status (52.5\%) and house ownership status $(67.7 \%)$ are the socio-economic factors that significantly necessitated the utilization of health care services by rural dwellers of Bauchi State.

\section{TESTING RESEARCH HYPOTHESIS}

Socio-economic factors do not have significant influence on the utilization of health care services by rural dwellers of Bauchi State.

Table 3 shows the influence of socio-economic factors on the utilization of health care services by rural dwellers of Bauchi State. The results obtained showed that, Education status, Occupation, Income, education, healthcare, type of house, age, marital status and insurance, do not have influence on the utilization of health care services $(\mathrm{P}>0.05)$. This probably suggests that there are other socio-economic factors that are not mentioned here but may have influence on utilization of healthcare. 
Table 3: The influence of socio-economic factors on the utilization of health care services by rural dwellers of Bauchi State

\begin{tabular}{|c|c|c|c|c|c|c|c|c|c|}
\hline & & Edu. Status & Occupation & Income & Education & Utilization & age & Marital Status & Insurance \\
\hline \multirow[t]{3}{*}{ Edu. Status } & Pearson Correlation & 1 & $0.952^{* *}$ & $0.900^{*}$ & $-0.236^{* \bullet}$ & -0.013 & 0.000 & 0.006 & 0.028 \\
\hline & Sig. (2-tailed) & & 0.000 & 0.000 & 0.000 & 0.458 & 0.978 & 0.722 & 0.104 \\
\hline & $\mathrm{N}$ & 3447 & 3447 & 3447 & 3447 & 3447 & 3447 & 3447 & 3447 \\
\hline \multirow[t]{3}{*}{ Occupation } & Pearson Correlation & $0.952^{* *}$ & 1 & $0.909^{* *}$ & $-0.234^{* *}$ & -0.022 & 0.004 & 0.001 & 0.029 \\
\hline & Sig. (2-tailed) & 0.000 & & 0.000 & 0.000 & 0.206 & 0.834 & 0.930 & 0.092 \\
\hline & $\mathrm{N}$ & 3447 & 3447 & 3447 & 3447 & 3447 & 3447 & 3447 & 3447 \\
\hline \multirow[t]{3}{*}{ Income } & Pearson Correlation & $0.900^{* *}$ & $0.909^{* *}$ & 1 & $-0.216^{* *}$ & -0.017 & 0.006 & 0.000 & 0.023 \\
\hline & Sig. (2-tailed) & 0.000 & 0.000 & & 0.000 & 0.331 & 0.713 & 0.979 & 0.180 \\
\hline & $\mathrm{N}$ & 3447 & 3447 & 3447 & 3447 & 3447 & 3447 & 3447 & 3447 \\
\hline \multirow[t]{3}{*}{ education } & Pearson Correlation & $-0.236^{* *}$ & $-.234^{* *}$ & $-0.216^{* *}$ & 1 & 0.012 & -0.003 & 0.003 & -0.004 \\
\hline & Sig. (2-tailed) & 0.000 & 0.000 & 0.000 & & 0.493 & 0.849 & 0.842 & 0.800 \\
\hline & $\mathrm{N}$ & 3447 & 3447 & 3447 & 3447 & 3447 & 3447 & 3447 & 3447 \\
\hline \multirow[t]{3}{*}{ healthcare } & Pearson Correlation & $-0.236^{* *}$ & $-0.234^{* *}$ & $-0.216^{* *}$ & $1.000^{* *}$ & 0.012 & -0.003 & 0.003 & -0.004 \\
\hline & Sig. (2-tailed) & 0.000 & 0.000 & 0.000 & 0.000 & 0.493 & 0.849 & 0.842 & 0.800 \\
\hline & $\mathrm{N}$ & 3447 & 3447 & 3447 & 3447 & 3447 & 3447 & 3447 & 3447 \\
\hline \multirow[t]{3}{*}{ type of house } & Pearson Correlation & 0.003 & 0.007 & 0.006 & -0.030 & 0.020 & -0.020 & 0.014 & 0.001 \\
\hline & Sig. (2-tailed) & 0.879 & 0.661 & 0.712 & 0.077 & 0.244 & 0.238 & 0.400 & 0.939 \\
\hline & $\mathrm{N}$ & 3447 & 3447 & 3447 & 3447 & 3447 & 3447 & 3447 & 3447 \\
\hline \multirow[t]{3}{*}{ Utilization } & Pearson Correlation & -0.013 & -0.022 & -0.017 & 0.012 & 1 & 0.000 & 0.031 & 0.009 \\
\hline & Sig. (2-tailed) & 0.458 & 0.206 & 0.331 & 0.493 & & 0.997 & 0.073 & 0.612 \\
\hline & $\mathrm{N}$ & 3447 & 3447 & 3447 & 3447 & 3447 & 3447 & 3447 & 3447 \\
\hline \multirow[t]{3}{*}{ age } & Pearson Correlation & 0.000 & 0.004 & 0.006 & -0.003 & 0.000 & 1 & -0.021 & 0.006 \\
\hline & Sig. (2-tailed) & 0.978 & 0.834 & 0.713 & 0.849 & 0.997 & & 0.221 & 0.706 \\
\hline & $\mathrm{N}$ & 3447 & 3447 & 3447 & 3447 & 3447 & 3447 & 3447 & 3447 \\
\hline \multirow[t]{3}{*}{ MaritalStatus } & Pearson Correlation & 0.006 & 0.001 & 0.000 & 0.003 & 0.031 & -0.021 & 1 & -0.001 \\
\hline & Sig. (2-tailed) & 0.722 & 0.930 & 0.979 & 0.842 & 0.073 & 0.221 & & 0.964 \\
\hline & $\mathrm{N}$ & 3447 & 3447 & 3447 & 3447 & 3447 & 3447 & 3447 & 3447 \\
\hline \multirow[t]{3}{*}{ Insurance } & Pearson Correlation & 0.028 & 0.029 & 0.023 & -0.004 & 0.009 & 0.006 & -0.001 & 1 \\
\hline & Sig. (2-tailed) & 0.104 & 0.092 & 0.180 & 0.800 & 0.612 & 0.706 & 0.964 & \\
\hline & $\mathrm{N}$ & 3447 & 3447 & 3447 & 3447 & 3447 & 3447 & 3447 & 3447 \\
\hline
\end{tabular}




\section{Discussion}

Several socio-economic factors have been indicated as factors that are responsible for the utilization and outcome of health care services. The present study revealed that, education, employment status and house ownership status are the socio-economic factors that significantly necessitated the utilization of health care services by rural dwellers of Bauchi State. Omorogbe (2017) reported that $47 \%$ indicated that economic constraint has influence on their use and satisfaction with the health care provided. Also, cultural beliefs, recipients' age, spousal roles, access to multiple doctors, and staff-patient relationship, health education, income and occupation influenced their satisfaction/ utilization. This does not completely agree with the findings in this study. Saeed et al. (2016), also reported that men with higher income preferred the private health facilities, while those who completed tertiary education, those with health insurance and those who self-rated their health as very bad, bad or moderate preferred public facility. Self-employed men and those in informal employment, preferred other health facilities outside the formal public health service. Women with primary and secondary education preferred the private health facilities. Women with health insurance, those in middle and upper class income quintiles or those with self-rated bad and moderate health status or being relatively younger preferred the public facility to other health services. Self-employed women and those in informal employment preferred traditional treatment. In Ghana, there are important socio-economic gradients in the use of some healthcare services. In both sexes, those without insurance and rural residents preferred the pharmacy and traditional treatment. This agrees with the findings in the present study with reference to the role played by education and employment. According to Saeed et al. (2015), aged women experience worse health than men, as shown by functioning assessment, self-rated health, chronic conditions and functional limitations. Women have higher rates of healthcare utilization, as shown by significantly higher rates of hospitalization and outpatient encounters.

The findings in the present study indicated that there are other factors that influence the utilization of health care facilities other than education status, Occupation, Income, education, healthcare, type of house, age, marital status and insurance, do not have influence on the utilization of health care services. Saeed et al. (2016) however, indicated that insurance influence health care utilization, this contradicts the findings in this study.

\section{Conclusion}

In conclusion, the utilization of health care centers in Bauchi State is very low among the rural dwellers. Education, employment status and ownership of house are the major socio-economic status that has some worth influence on health care utilization in the study area. Also, there are other factors that influence the utilization of health care facilities other than 
education status, Occupation, Income, education, healthcare, and type of house, age, marital status and insurance.

\section{Recommendations}

Based on the conclusions drawn in this study, the following recommendation has become necessary. The non-educated or half literate, the unemployed and those who live in rented homes should be encouraged to utilize health facilities the more. Also, the influence of other socio-economic factors on health facilities utilization should be studied.

\section{Acknowledgements}

We which to appreciate Mr. W.O. Tanimowo for his help in analyzing the data used in this study.

\section{References}

Adam, V.Y ., Awunor, N.S. 2015. "Perceptions and factors affecting utilization of health services in a rural community in Southern Nigeria". Journal of Biomedical Sciences. 13(2), p. 117-124

Anderson, J.G. 1973. Health Service Utilization : Framework and Review. Health Service Research. p185- 199.

Awoyemi, T.T., Obayelu, O.A., Opaluwa, H.I. 2011. Effect of Distance on Utilization of Health Care Services in Rural Kogi State , Nigeria. Human Ecology. 35(1), p.1-9.

Babazono A, Kuwabara K, Hagihara A, Yamamoto E, Hillman A (2008) Does income influence demand for medical services despite Japan's "Health Care for All" policy? (abstract). Int J Technol Assess Health Care. Winter;24(1):125-30. doi: 10.1017/S0266462307080166. https://www.ncbi.nlm.nih.gov/pubmed/18218178

Bakeera, S.K., Wamala, S.P., Galea, S., State, A., Stefan Peterson, S. , Pariyo, G.W. 2009. Community perceptions and factors influencing utilization of health services in Uganda. International Journal for Equity in Health. 8:25. Retrieved from http://www.equityhealthj.com/content/8/1/25.

Bauchi State Government 2018. Nigeria - Official Website" (https://www.bauchistate.gov.ng//).

Bour, D. 2004. Determinants of utilisation of health services by women in rural and urban areas in Ghana. Geo Journal 61(1), p. 89- 102

Carraquillo, O. 2013. Health Care Utilization. Encyclopedia of Behavioural Medicine. Ed. Retrived from https://link.springer.com/referenceworkentry/10.1007\%2F978-1-4419-1005-9_885

Fang, P., Han, S., Zhao, L., Fang, Z., Zhang, Y., Zou, X. 2014. What limits the utilization of health services among the rural population in the Dabie MountainsEvidence from Hubei province, China? BMC Health Services Research. 14 (379), p. 1 - 7

Gam-Yadam, A., Shinohara, R., Sugisawa, Y., Tanaka, E, Watanabe, T., Hirano, M., Tomisaki, E., Morita, K., Ona, Y., Tokutake, K., Mochizuki, Y., Matsumoto, M., Sugita, C, Anme, K. 2013. Factors Associated With Health Service Utilization in Ulaanbaatar, Mongolia: A Population-Based Survey. J Epidemiol, p. 1-9

Girma, F., Jira, C., Girma, B. 2011. Health Services Utilization and Associated Factors In Jimma Zone, South West Ethiopia. Ethiop J Health Sci. 21, 86, p. 85- 94.

Healthy People 2020 .2018. Environmental health. Retrieved from https://www.healthypeople.gov/2020/topics-objectives/topic/environmental-health

Hsu, J. 2010. The relative efficiency of public and private service delivery. WashingtonDC, MA: World Health Organization.

Jayadevappa, R., Chhatre, S. 2011. Patient Centered Care - A Conceptual Model and Review of the State of the Art. The Open Health Services and Policy Journal, 4(3), p.15-25. 
MACPAC (Medicaid and CHIP Payment and Access Commission). 2016. Medicaid access in brief: Adults' experiences in obtaining medical care. Washington, DC: MACPAC. https://www.macpac.gov/wp content/uploads/2016/11/Adults-Experiences-in-Obtaining-Medical-Care.pdf (accessed November 19, 2018).

Ministry of Health. 2003. Kenya Household Health Expenditure and Utilization Survey. Nairobi.

Mohammadbeigi, A., Arsangjang, .S., Mohammadsalehi, N., Anbari, Z., Ghaderi , E. 2015. Education-related Inequity in Access and Utilization of Oral Health Care in Iran. J Family Med Prim Care. 2015 Jan-Mar; 4(1), p. 35-38.

Moyer, C. A., Adongo, P. B., Aborigo, R. A., Hodgson, A., Engmann, C. M. 2014. 'They treat you like you are not a human being': Maltreatment during labour and delivery in rural northern Ghana. Midwifery, 30(2), p. 262-268.

Mwonjoria, M.A. 2014. factors influencing utilization of health services of private health facilities in thika sub-county: insights for strategic healthcare management. An unpublished Dissertation Submitted to the Chandaria School of Business in Partial Fulfillment of the Requirement for the Degree of Masters of Science in Business Administration, UNITED STATES INTERNATIONAL UNIVERSITY, Nairobi, Kenya

NCHS. 2016. Health, United States. In Health, United States, 2015: With special

Ngugi, A.K., Agoi, F., Mahoney, M.R., Lakhani, A., Mang'ong'o, D., Nderitu, E., Armstrong, R., Macfarlane, S. 2017. Utilization of health services in a resource-limited rural area in Kenya: Prevalence and associated household-level factors. PLoS ONE 12(2): e0172728https://doi.org/10.1371/journal.pone.0172728

Ngwakongnwi, E. 2017. Measuring health services utilization in ethnic populations: Ethnicity and choice of frameworks. Public Health Open J. 2(2), p. 53-58. doi: $10.17140 / \mathrm{PHOJ}-2$

Nigussie, M., Haile, M.D., Mitike, G. 2004. Assessment of safe delivery service utilization among women of childbearing age in north Gondar Zone, North West Ethiopia. Ethiop. J.Health Dev. 18(3), p. 145-152.

Oladipo, J.A. 2014. Utilization of health care services in rural and urban areas: a determinant factor in planning and managing health care delivery systems.

African Health Sciences. 2014 Jun; 14(2), p. 322-333.

Oluyemi, .J. Abubakar, .M., Abdullateeef, R., Akindele, .I., Adejoke, .J., Kairi, .K. 2018. Factors Determining the Utilization of Healthcare Facilities in SemiUrban Setting in Kwara State of Nigeria. Anthropological Research and Studies. 8. Retrieved from http://www.journalstudiesanthropology.ro/en/no-8$2018 /$ r86/

Omorogbe, C.E. 2017. Socio-Economic Factors Influencing In-Patient Satisfaction with Health Care at the University of Benin Teaching Hospital (UBTH), Benin City, Nigeria. International Journal of Nursing, Midwife and Health Related Cases. 3(4), p. 1-17.

Omorogbe, C.E. 2017. Socio-Economic Factors Influencing In-Patient Satisfaction with Health Care at the University of Benin Teaching Hospital (UBTH), Benin City, Nigeria. International Journal of Nursing, Midwife and Health Related Cases. 3(4), p. 1-17.

Onyeneho, N.G., Amrazigo, U.V., Njepuome, N.A., Nwaorgu, O.C., Okeibuno, J.C. 2016. Perception and utilization of public health services in Southeast Nigeria: Implication for health care in communities with different degrees of Urbanization. International Journal for Equity in Health . 15:12 https://doi.org/10.1186/s12939-016-0294-z

Owens, G. M. 2008. Gender differences in health care expenditures, resource

Prosser, T (2007). Utilization of health and medical services: factors influencing health care seeking behaviour and unmet health needs in feature on racial and ethnic health disparities. Hyattsville, MD: National Center for Health Statistics (US).

Rumum, A.J. 2014. Influence of Religious Beliefs on Healthcare Practice. International Journal of Education and Research. 2(4): 37 - 48

Saeed, B. I. I., Yawson, A. E., Nguah, S. Agyei-Baffour,.P., Nakua, E., and Ayesu, E. (2016). Effect of socio-economic factors in utilization of different healthcare services among older adult men and women in Ghana. BMC Health Services Research (2016) 16:390 . DOI 10.1186/s12913-016-1661-6

Saeed, B.I.I., Xicang, Z., Yawson, A.E., Nguah, S.B. and Nsowah-Nuamah, N.N.N. (2015). Impact of socioeconomic status and medical conditions on health and healthcare utilization among aging Ghanaians. BMC Public Health. 15(276), p. 1- 9.

Schiller,P.L. Levin, J.S. 1988. Is There A Religious Factor In Healthcare Utilization?: A Review. Soc. Sci. Me 27912, p. 1369- `379

Uchendu, O.C., Ilesanmi, O.S., Olumide, A.E. 2013. Factors Influencing the Choice Of Health Care Providing Facility Among Workers In A Local Government Secretariat in South Western Nigeria Annals of Ibadan Postgraduate Medicine.Vol.11, No.2 87-95 utilization, and quality of care. Journal of Managed Care \& Specialty Pharmacy. 14(3 Suppl), p. 2-6.

Xu, K., Carrin, G., Phuong,N.T.K., Long,N.H., Bayarsaikhan,.D., Aguilar, A.N (2006). Health service utilization and the financial burden on households in Vietnam: the impact of social health insurance. World Health Organisation. Department "Health System Financing" (HSF) Geneva 